\title{
ACESSO À JUSTIÇA E ATUAÇÃO DO PODER JUDICIÁRIO PARA IMPLEMENTAÇÃO DO DIREITO FUNDAMENTAL AO MEIO AMBIENTE
}

\author{
Luiz Gustavo Gonçalves Ribeiro ${ }^{1}$ \\ Ariadne Elloise Coelho ${ }^{2}$
}

\section{Resumo}

O estudo tem por escopo o exame do controle judicial na aplicação do direito fundamental ao meio ambiente ecologicamente equilibrado ante a inércia dos demais poderes, além do concernente à melhor adequação dos intérpretes do direito quanto ao acesso à justiça, em vista das diretrizes e determinações constitucionais. A análise, que é jurídico-teórica, calca-se no raciocínio lógico-dedutivo e constata a exigência de repensar a atividade judicante com espeque no discurso jurídico, sem o realce do argumento puramente político, balizada nas necessidades sociais.

Palavras-Chave: Meio Ambiente; Omissão; Acesso e atuação do Poder Judiciário; Método teórico.

\section{ACCESS TO THE JUSTICE AND ACTION OF THE JUDICIARY FOR THE IMPLEMENTATION OF FUNDAMENTAL LAW TO THE ENVIRONMENT}

\begin{abstract}
The scope of this study is the examination of judicial control in the application of the fundamental right to the ecologically balanced environment, given the inert of the other powers, and the ideal adequacy of the interpreters of the law regarding access to justice, in view of the constitutional guidelines and determinations. The analysis, which is legaltheoretical, is based on logical-deductive reasoning and notes the requirement to rethink the judicial activity with a special focus on legal discourse, without highlighting the purely political argument, based on social needs.
\end{abstract}

Keywords: Environment; Omission; Access and operation of the Judiciary; Theoretical method.

\section{INTRODUÇÃO}

1 Pós-Doutor pela Università Degli Studi di Messina/IT. Doutor e Mestre em Ciências Penais pela UFMG. Professor do curso de Mestrado em Direito Ambiental e Desenvolvimento Sustentável da Escola Superior Dom Helder Câmara. Promotor de Justiça em Belo Horizonte-MG.

2 Mestranda em Direito Ambiental e Desenvolvimento Sustentável pela Escola Superior Dom Helder Câmara. Especialista em Ciências Penais pela Pós-Graduação Lato Sensu do Instituto de Educação Continuada na Pontifícia Universidade Católica de Minas Gerais — IEC PUC Minas. Bacharela em Direito pelo Centro Universitário Newton Paiva. 
A pesquisa tem por objetivo debater, respeitadas as limitações do texto, a atividade jurisdicional supletiva de políticas públicas socioambientais, bem como o mais amplo acesso à justiça em prol do meio ambiente segundo paradigmas constitucionais.

A opção pelo enfoque justifica-se não apenas em face do reconhecimento constitucional do meio ambiente equilibrado à existência e qualidade de vida de todos, mas também em vista da adequada concretização desse direito e do correspondente dever de sua proteção, proporcional aos possíveis impactos ambientais.

O aumento de ações judiciais envolvendo a abstenção de prestações materiais na seara social tem esbarrado em problemas no equacionamento entre o ativismo arbitrário e o passivismo violador de direitos fundamentais. E, a despeito disso, ainda se encontra demandas suprimidas pela contraditória barreira de ingresso da população nas discussões essenciais ao seu pleno desenvolvimento e dignidade.

Intenta-se analisar os posicionamentos doutrinários e jurisprudenciais, bem como as dificuldades práticas do sistema judiciário, normatizadas ou internalizadas, com o propósito único de contribuir para o aperfeiçoamento dos fatores a ele relacionados. Eis a importância do tema e da exposição que se propõe.

A análise principia com considerações preliminares sobre a importância do meio ambiente, tutelado constitucionalmente como direito, que implica assunção de encargos pelo Poder Público e pela coletividade. Com base nessas premissas, são discutidos alguns dos principais aspectos pertinentes à carência da exequibilidade.

Em continuidade, analisa-se a recorrente procura pelo Judiciário como aplacador da omissiva estatal, haja vista ter se tornado a única opção possível, conquanto controvertida em sua legitimidade judicante de aplicar políticas públicas e/ou efetivar direitos fundamentais, sobretudo em razão do perigo de um poder tirano naquele que é visto na sociedade como bastião da moralidade.

Por fim, busca-se apontar a falha da ação popular, que limita o acesso do cidadão atingido ou alijado de seus direitos socioambientais, o que demonstra ser só mais um resquício do caráter excludente do direito, que necessita urgentemente de reconstrução para que opere como verdadeiro instrumento de transformação social.

O tema é abordado numa perspectiva crítica, por meio de pesquisa bibliográfica, prestando-se a elucidar um problema atual, que exige uma redefinição da função do Estado 
em prol de uma população que sequer conhece seus direitos ou mesmo detém acesso às vias para reivindicá-los, contrariando a aspiração da Constituição.

Inclina-se ao diálogo com o fim de proporcionar o amadurecimento da práxis do Direito, que deve estar sempre atrelada à seriedade de sua atuação na consecução dos significados da coletividade.

O raciocínio lógico-dedutivo apoia-se na tese de que o direito socioambiental é fundamental e que, diante da antítese de omissão do Poder Público, tem-se a síntese de que o Poder Judiciário deve intervir, quando demandado for pelos mais diversos meios de acesso à justiça, em prol das necessidades sociais.

À pergunta se há espaço para que o judiciário interfira no controle da execução dos direitos preconizados constitucionalmente, no caso o meio ambiente, tem-se que, ante a omissão dos demais poderes, ele pode e deve intervir, em um espaço em que, dada a magnitude do direito a ser defendido, deve ser amplo o acesso à justiça.

\section{O MEIO AMBIENTE E AS MAZELAS DO ESTADO NA SUA EFETIVA TUTELA}

A importância do meio ambiente tem seu apogeu no cenário brasileiro com o advento da Constituição da República de 1988, que institui ampla proteção e o dever de todos, Estado e coletividade, na defesa e preservação ambiental. Trata-se de direito a um meio ecologicamente equilibrado, estendido a todos, inclusive às gerações vindouras, posto que essencial à sadia qualidade de vida (BRASIL, 1988).

Da leitura do texto constitucional é possível extrair que a tutela está intimamente ligada à salvaguarda da própria vida e, mais que isso, a uma existência com qualidade. Principalmente por isso, tem-se entendido que o meio ambiente é um direito fundamental, elementar ao bem do homem e ao gozo de todos os direitos fundamentais, da atual e futura sociedade (GIONGO, 2010, p. 87).

Há quem promova o meio ambiente ao direito à vida, eis que lhe atribui dignidade e, assim, o desenvolvimento. É que "a proteção do direito a vida está garantido, sim, com `Vida antes da Vida`. Ou melhor, o direito e proteção dos não nascidos está garantido na própria Constituição brasileira, quando expõe, em seu art. 225, o direito das gerações futuras". (COSTA, 2010, p. 113).

Portanto: 
[...] é correto afirmar que o direito à vida condiciona todos os demais direitos, mas o acesso a esse direito de defesa está intimamente ligado ao meio ambiente, que deve ser protegido de riscos ambientais sérios à vida. O meio ambiente também deve ser protegido como o direito de defesa da vida, ou melhor, como o local fundamental do desenvolvimento da personalidade humana. (COSTA, 2010, p. 117).

De mais a mais, os direitos fundamentais são concebidos além daqueles dispostos no artigo $5^{\circ}$ da Constituição de 1988, compreendendo diversos outros estabelecidos, explícita ou implicitamente, em demais títulos e capítulos, por disposta receptividade do $\S 2^{\circ}$, do referido dispositivo. (THOMÉ, 2014, p. 123).

$\mathrm{E}$ as consequências de um ambiente desequilibrado podem ser devastadoras e permanentes, alcançando, inclusive, locais, pessoas e demais seres, geograficamente e temporalmente, distantes. E a espécie humana não é só a que mais contribui para esse desequilíbrio, mas também é a mais atingida por essas alterações ambientais.

Por isso, o motivo de se preocupar com as sucessoras gerações, eis que a humanidade, pela interpretação de Alexandre Kiss, inclui os membros atuais e futuros, não existindo a possibilidade de separar, nesse contexto, uma geração da outra:

[...] de forma conceitual, o principal problema é que não há nenhuma geração distinta. Em cada duas centenas de seres humanos que nascem e morrem, mas de cinco bilhões de pessoas de todas as idades coexistem. Seria mais exato falar não de gerações, mas de um fluxo constante; a humanidade pode ser comparada a um enorme rio que flui constantemente, torna-se cada vez maior e nele nenhuma distinção pode ser feita entre as gotas de água que o formam. (KISS apud VARELLA; PLATIAU, 2004, p. 4)

Hans Jonas constata que a descoberta pelo homem de ser o único capaz (tem poder tecnológico e bélico) de extinguir a natureza, e de que essa destruição poderá levar ao fim da própria humanidade, é que o impeliu à preocupação com o futuro, (re) visitando uma ética de responsabilidade em prol não somente de sua espécie, mas do todo (JONAS, 2006).

Assim, o meio ambiente foi identificado como direito fundamental de terceira geração ou dimensão, por transcender o caráter individual, ligado aos direitos difusos (FIORILLO, 2014, p. 37), em que se “[...] enxerga como destinatário todo o gênero humano (presente e futuro), como um todo conectado, de modo que se fundamentaria no princípio da fraternidade (ou segundo alguns, no da solidariedade)”. (FERNANDES, 2013, p. 316)

Fato é que essa reflexão, em âmbito mundial, apenas ocorreu diante de inúmeras catástrofes ambientais espalhadas pelo globo terrestre e a necessidade de se discutir 
seriamente sobre a esgotabilidade dos recursos e a indispensabilidade do meio ambiente (COSTA, 2010, p. 35), sobretudo com a Conferência de Estocolmo de 1972 (THOMÉ, 2014, p. 122), quando se solidificaram os princípios e as diretrizes da temática.

A partir disso, despontou-se a ideia de equacionar a questão econômica com a preservação ambiental e a equidade social, traduzida no princípio do desenvolvimento sustentável e expressada na interpretação dos artigos 170 e 225 da Constituição de 1988 (THOMÉ, 2014, p. 148-151).

Isso porque a grande dificuldade no cuidado com o meio ambiente habita no peso do poderio econômico-financeiro, gananciado pelo homem, sem olvidar a necessidade de educação, informação e conscientização ambiental de cada um. Romeu Thomé explica que é preciso reverter esse quadro, considerando-se verdadeiramente o meio ambiente como forma de equilibrar os pilares do desenvolvimento sustentável:

[...] o meio ambiente ecologicamente equilibrado é condição prévia e essencial para a implementação dos demais sustentáculos, quais sejam, equidade social e crescimento econômico. Sem condições ambientais saudáveis, caem por terra todas as conquistas individuais e sociais alcançadas pelo ser humano, não havendo que se falar, muito menos, em busca de objetivos futuros, como de crescimento econômico. Portanto, não remanescem dúvidas de que, dos três pilares do desenvolvimento sustentável, a proteção ambiental representa o seu pilar central, de sustentação, e assim ele deve passar a ser considerado ao se interpretar as normas vigentes no ordenamento jurídico pátrio. Entretanto, na prática, sobretudo na atuação dos Poderes Legislativo e Executivo no Brasil, constata-se que, quando há oportunidade de equilibrar os três valores, a balança, na grande maioria das vezes, pende para o crescimento econômico, em prejuízo da proteção dos direitos fundamentais socioambientais. (THOMÉ, 2014, p. 154155). (grifos do autor).

Mas a realização plena dos direitos ambientais é mais dependente de políticas públicas "do que de mudanças particulares, pois se pode decidir pessoalmente pela responsabilidade com o futuro da humanidade, mas a consumação está em um nível planetário e estatal”. (COSTA; REIS; OLIVEIRA, 2016, p. 24). Ora, o meio ambiente é preocupação coletiva, pois as consequências de seu desequilíbrio atingem toda a população.

Com efeito, o mandamento constitucional estabeleceu deveres específicos ao poder público, como os enumerados nos sete incisos do $\S 1^{\circ}$ do artigo 225 (BRASIL, 1988). No entanto, há um permanente descaso estatal em termo de implementação de suas obrigações sociais, posto carecer de ações positivas, isto é, prestacionais, que demandam recursos do erário - e isso não é diferente na seara socioambiental. 
A abstenção dos poderes legislativo e executivo, ordinariamente responsáveis pela elaboração e execução de atividades específicas de defesa e preservação do meio ambiente, tem implicado no aumento da procura pelo controle judicial, cuja atuação, a priori extraordinária, é cada vez mais comum, embora questionada.

Mas nem essa provocação do poder judiciário tem sido utilizada para implementar políticas públicas socioambientais, seja pela falta de interesse pela demanda ambiental seja por esquiva do próprio poder de decisão, o que demonstra a urgência de mudança de paradigma dos meandros do tema.

Além disso, há dificuldade naturalizada no acesso do cidadão ao Judiciário, em razão do tradicionalismo milenar do direito, com interferência obsoleta em instrumentos judiciais que, em sua essência, ampliariam o espaço de participação social.

Se, como supradelineado, o meio ambiente equilibrado é requisito para a usufruição dos demais direitos fundamentais, a abstenção do poder público ofende todo um sistema jurídico, rebaixando os preceitos constitucionais a meras promessas, sem eficácia, legitimando uma violência simbólica que, para Jessé Souza, “[...] torna possível a naturalização de uma desigualdade social abissal como a brasileira". (SOUZA, 2009, p. 15).

O primeiro passo é reconhecer o meio ambiente como imprescindível à própria vida, o "que fará com que a proteção do ambiente seja matéria obrigatória para os três Poderes Nacionais do Estado, ou seja, Poder Legislativo, Poder Executivo e Poder Judiciário" (COSTA, 2010, p. 114).

\section{A JUdicializaÇÃo DE POLÍticas PÚBlicas AMBIENTAIS: UM CAMINHO?}

O Poder Público tem obrigação constitucional de proteger e preservar o meio ambiente ecologicamente equilibrado, e esse dever é concretizado (ou assim deveria), principalmente, por meio de políticas públicas, consistentes em atividades voltadas à consecução dos fins do próprio Estado.

É que a Constituição de 1988 elegeu os objetivos fundamentais da República Federativa do Brasil no artigo $3^{\circ}$, dentre os quais se destacam aqueles previstos nos incisos I, "construir uma sociedade livre, justa e solidária", e III, "erradicar a pobreza e a marginalização e reduzir as desigualdades sociais e regionais" (BRASIL, 1988). 
Tais intentos remetem à ideia de politicas sociais e solidárias, envolvendo direitos à saúde, à educação, ao meio ambiente sadio, isto é, dependentes de posturas prestacionais que possibilitem a fruição das garantias constitucionalizadas. Carmen Lúcia explica:

Verifica-se que todos os verbos utilizados na expressão normativa - construir, erradicar, reduzir, promover - são de ação, vale dizer, designam um comportamento ativo. O que se tem, pois, é que os objetivos fundamentais da República Federativa do Brasil são definidos em termos de obrigações transformadoras do quadro social e político retratado pelo constituinte quando da elaboração do texto constitucional. (ROCHA, 1996, p. 285).

Também se extrai da Lei n. 6.938/81, que dispõe sobre a Política Nacional do Meio Ambiente, em seu artigo $2^{\circ}$, caput, a interlocução entre preservação do meio ambiente e desenvolvimento socioeconômico, destacando-se, no inciso I, o dever da "ação governamental na manutenção do equilíbrio ecológico, considerando o meio ambiente como um patrimônio público a ser necessariamente assegurado e protegido, tendo em vista o uso coletivo" (BRASIL, 1981).

O problema que se enfrenta é de omissão da Administração Pública na elaboração e implementação de políticas públicas na seara ambiental, mesmo porque a abstenção já é comum em relação aos direitos sociais. O Poder Legislativo e, ainda mais, o Executivo, a quem compete primariamente a adoção de medidas protetivas ambientais, mantem-se frequentemente inerte, muitas vezes por pura conveniência.

Com efeito, discute-se a possibilidade do controle judicial das políticas públicas previstas e não estabelecidas, como último recurso da sociedade, que se vê ofendida em seus direitos e garantias fundamentais.

Essa intervenção do Judiciário nas atividades dos demais poderes é bastante controversa na doutrina e imperada por críticas, relacionadas à suposta interferência na discricionariedade administrativa; na questão orçamentária do Estado e no desrespeito à teoria da separação dos poderes.

Ademais, povoa o medo de que surja um super poder, formado por juízes, com a politização do direito, "pois o regime democrático não se coaduna com a concentração extremada de poder político junto a um único órgão”. (APPIO, 2007, p. 71).

Fato é que mesmo a discricionariedade pode ser revista pelo Judiciário, uma vez fora dos limites legais e dos "princípios constitucionais da legalidade, impessoalidade, moralidade, publicidade, eficiência, razoabilidade, proporcionalidade, igualdade e motivação" (THOMÉ, 2014, p. 219). 
Desde a Lei da Ação Popular, a apreciação do mérito administrativo pelo Judiciário também pode ocorrer com a mera lesividade, possibilitando a nulidade do ato sem o requisito da ilegalidade (BRASIL, 1965), previsão trazida pela Constituição de 1988 (artigo 5º, inciso LXXIII), legitimando a análise do mérito administrativo no ato lesivo à moralidade administrativa (BRASIL, 1988).

Quanto ao discurso orçamentário, Álvaro Ricardo evidencia a associação ao velho enunciado liberal de que a dimensão prestacional dos direitos sociais, e a consequente escassez de recursos públicos, dificultaria sua efetivação em relação aos direitos individuais. Contudo, esquece-se que mesmo os direitos individuais demandam dinheiro: ou o resguardo da segurança/integridade física e da propriedade das pessoas prescinde de alocação de recursos para a manutenção do aparato policial e judicial? (CRUZ, 2007, p. 335/336).

Eduardo Appio, neste aspecto, destaca que:

as decisões judiciais fundamentadas exclusivamente em razões de ordem econômica e no equilíbrio fiscal, de cunho consequencialista, representam verdadeira negação de justiça e não podem ser justificadas no plano racional-jurídico, muito embora possam ser respaldadas a partir de argumentos políticos e sociais. (APPIO, 207, p. 73).

Os objetivos impostos pela Constituição de 1988 (e repetidos nas legislações e normas infraconstitucionais) exigem um atuar do Estado, portanto, de todos os poderes que o expressam, o que inclui a atividade do Poder Judiciário, que não pode ser mais limitada a uma postura neutra, incompatível com a necessidade contemporânea (GRINOVER, 2013, p. 129).

A interpretação atual da teoria de Montesquieu está, essencialmente, nos princípios de integração e de equilíbrio. A adequada separação de poderes confere a cada fração representativa do Estado a atribuição com base em colaboração e controle, que caracterizam o equilíbrio que persegue o chamado sistema de freios e contrapesos.

Trata-se de mudança paradigmática em consonância com a realidade fática e jurídica brasileira, e, segundo Ada Pellegrini, da evolução de um Estado Liberal e Social para um Estado Democrático de Direito, em que o Poder Judiciário deve estar ajustado aos objetivos do Estado, que 'tem de se organizar no facere e praestare, incidindo sobre a realidade social". (GRINOVER, 2013, p. 128-129).

O Poder Judiciário tem, nessa esteira, o controle de constitucionalidade das leis editadas e as decisões sobre o cumprimento dos deveres sociais estatais via ações coletivas. Ambos os casos exigem provocação inicial de terceiros legitimados. 
E o próprio Judiciário, quando acionado, tem reconhecido como legítima a intervenção para suprir a omissão legislativa ou executiva. Mais que isso: o agir positivo é dever institucional sob o comando constitucional, segundo afirmado em alguns julgados do Supremo Tribunal Federal. ${ }^{3}$.

Não se olvida da compatibilização de requisitos para a atuação judicial, baseados no mínimo existencial, razoabilidade e reserva do possível, bem como as vias processuais adequadas a provocar o controle nas políticas públicas, incluindo as ações individuais e coletivas (GRINOVER, 2013, p. 132-150).

Mas também não se pode servir de artifícios perpétuos e arbitrários para frustrar o cumprimento de obrigações constitucionais pelo Poder Público, sob o falso argumento de serem desprovidas de eficácia jurídica.

Na seara ambiental, englobando tanto direitos individuais quanto direitos sociais, é viável a submissão ao controle judicial de transgressões ao direito fundamental ao meio ambiente ecologicamente equilibrado, tendo em vista a determinação constitucional de sua proteção pelo Poder Público.

Como exemplo de demandas ambientais, tem-se a destinação inadequada de lixo urbano; a poluição de rios pelo lançamento de esgotos sem o devido tratamento; e a degradação de ecossistemas e áreas naturais de relevância ecológica. Os julgados ora obrigam que a Administração observe de forma imediata o dever constitucional, a qualquer custo e sem planejamento, ora que se destine no orçamento verba própria para cumprimento do encargo. ${ }^{4}$

Parece-se olvidar ou desconhecer que há substancial distinção em se decidir com argumento de política pública ou de direito fundamental, eis que, no primeiro caso, estende-se o decisum a toda população, concedendo o pleito não somente ao cidadão que buscou a via judicial para efetivação do seu direito.

Ao se decidir com política pública, é preciso parcimônia para que não se revitimize o cidadão, cabendo, por exemplo, a determinação de que a implantação do direito seja incluída no próximo orçamento do ente estatal responsável ao invés de se exigir a imediata execução, a custo da própria comunidade, aviltando o ideal de justiça.

\footnotetext{
${ }^{3}$ A título de exemplo: AI 583.136/SC; RTJ 185/794-796 e RTJ 199/1219-1220.

${ }^{4}$ Nesse sentido: AC $10082120006448001 \mathrm{MG}$ e AC 200650030001363 RJ.
} 
$\mathrm{Na}$ verdade, a constatada confusão reflete, como dito, a ausência de conhecimento e informações que propiciem um julgamento adequado e justo pelo juiz e uma necessidade preeminente de reforma, entre um passivismo violador inaceitável e um ativismo tirano antidemocrático.

\section{O PARAdigma do ACESSO À JUSTIÇA E A AÇÃo POPUlAR NA QUESTÃo AMBIENTAL}

O advento da Constituição de 1988, seguindo um processo de redemocratização, concedeu credibilidade e ampliou o "uso da via judicial como alternativa para alcançar direitos" (SANTOS, 2011, p. 25), inclusive com a utilização de instrumentos jurídicos, outrora sem eficácia, como a ação popular e a ação civil pública.

Alia-se a isso, como já esmiuçado, a precarização dos direitos sociais e a abstenção deliberada do poder público, causando a acentuada busca pela resolução judicial na defesa dos direitos caros à sociedade.

Ainda assim, parcela da população tem sua procura suprimida, pois, como destaca Boaventura, sente-se impotente para reivindicar seus direitos no Judiciário:

[...] ficam totalmente desalentados sempre que entram no sistema judicial, sempre que contatam com as autoridades, que os esmagam pela sua linguagem esotérica, pela sua presença arrogante, pela sua maneira cerimonial de vestir, pelos seus edifícios esmagadores, pelas suas labirínticas secretarias etc. Esses cidadãos intimidados e impotentes são detentores de uma procura inviabilizada. (SANTOS, 2011, p. 38).

Prova dessa limitação de acesso está na legitimidade para propositura de ação popular em defesa ambiental, que se trata de instrumento de tutela dos interesses da coletividade, com gênese no direito romano, inicialmente prevista nas Constituições de 1934, 1946 e 1967 (e na Emenda Constitucional n. 1/69). (FIORILLO, 2014, p. 802/805). Mesmo na lei específica n. 4.717/65 (BRASIL, 1965), seu cunho era eminentemente patrimonial, o que só mudou com o novo marco constitucional, que expandiu seu objeto, alcançando a moralidade administrativa e o meio ambiente - artigo $5^{\circ}$, inciso LXXVIII:

Qualquer cidadão é parte legítima para propor ação popular que vise a anular ato lesivo ao patrimônio público ou de entidade de que o Estado participe, à moralidade administrativa, ao meio ambiente e ao patrimônio histórico e cultural, ficando o 
autor, salvo comprovada má-fé, isento de custas judiciais e do ônus da sucumbência. (BRASIL, 1988). (Grifo nosso).

No plano infraconstitucional, uma vez recepcionada pela Constituição de 1988, a Lei n. 4.717/1965, em seu artigo $1^{\circ}, \S 3^{\circ}$, especifica como legitimado apenas aquele que ostente a condição de cidadão, isto é, a pessoa física no gozo de seus direitos políticos, confirmada pela juntada em juízo do título de eleitor ou de documento correspondente.

Ocorre que esse conceito de cidadão era adequado aos casos de proteção da coisa pública, antes da amplificação ao meio ambiente, cujo destinatário é toda a coletividade. Isso porque não é somente o eleitor o afetado por ameaças e lesões ambientais, mas qualquer pessoa, brasileira ou não, residente no país.

Aliás, trata-se de interpretar sistematicamente a vontade do constituinte ao preceituar “todos", no artigo $5^{\circ}$, caput, "todos são iguais perante a lei, sem distinção de qualquer natureza, garantindo-se aos brasileiros e aos estrangeiros residentes no País a inviolabilidade do direito à vida, à liberdade, à igualdade, à segurança e à propriedade, [...]:”, e no artigo 225, caput, "todos têm direito ao meio ambiente ecologicamente equilibrado, bem de uso comum do povo e essencial à sadia qualidade de vida, impondo-se ao Poder Público e à coletividade o dever de defendê-lo e preservá-lo para as presentes e futuras gerações”.

Nesse sentido, José Sérgio Monte Alegre, mencionado por Celso Antônio Pacheco Fiorillo, esclarece:

[...] a palavra cidadão, na linguagem constitucional, não é sempre equivalente perfeito de eleitor. Prova de que não se acha no art. 64 do ADCT, pois do contrário somente o eleitor teria direito a receber um exemplar da Constituição Federal, isso apesar de todos os brasileiros estarem igualmente sujeitos às suas disposições! Porém, não só ali. No $\mathrm{n}$. $\mathrm{V}$, do $\S 2^{\circ}$ do art. 58 , há também prova de que não existe relação necessária entre cidadão e eleitor, porquanto, se houvesse, as Comissões da Câmara e do Senado, ou as do Congresso Nacional, não poderiam solicitar depoimentos a não ser de autoridades e eleitores! E mais: a insistir-se na ideia de equivalência, apenas o partido político, a associação, o sindicato ou o eleitor poderiam representar ao Tribunal de Contas contra irregularidades ou ilegalidades, enquanto qualquer pessoa poderia dirigir às comissões parlamentares, do Congresso, da Câmara e do Senado, petições, reclamações, representações ou queixas contra atos das autoridades ou entidades públicas, quaisquer que sejam, o que seria rematada estultice, dessa de fazer corar um frade de pedra! Daí se segue que, se a um mesmo vocábulo o texto atribui significados descoincidentes, o acertado é darlhe, em cada caso, o sentido mais ajustado à finalidade do sistema inteiro, porque é de sistema que se trata [...]. (ALEGRE apud FIORILLO, 2014, p. 809/810). (Destaques nossos). 
Por esse motivo, Fiorillo sustenta que, no que pertine à proteção ambiental, o artigo $1^{\circ}, \S 3^{\circ}$, não foi recepcionado pelo atual modelo constitucional. (FIORILLO, 2014, p. 809). Mesmo porque se o Ministério Público - e qualquer outro cidadão - tem o condão de continuar no prosseguimento da ação, na hipótese de desistência do autor, segundo artigo $7^{\circ}$, inciso II, da Lei n. 4.717/65 (FERNANDES, 2013, p. 546), não há sentido em restringir o rol de legitimados.

A questão é a mesma assentada pelo Supremo Tribunal Federal no julgamento da Ação Declaratória de Inconstitucionalidade n. 3.943, que considerou constitucional a atribuição da Defensoria Pública em propor ação civil pública. A despeito de incluída no rol dos legitimados da Lei n. 7.347/85, em 2007, a Associação Nacional dos Membros do Ministério Público questionou essa previsão.

Destaca-se trecho do voto da Ministra relatora, Carmen Lúcia, que intercedeu pela ampliação dos legitimados na defesa da coletividade, mormente em um país marcado por tensa desigualdade, em que o acesso à justiça configura barreira inegável da democracia e cidadania: "O dever estatal de promover políticas públicas tendentes a reduzir ou suprimir essas enormes diferenças passa pela operacionalização dos instrumentos que atendam com eficiência a necessidade de seus cidadãos".

Embora aponte para a devida extensão dos legitimados ativos na ação popular, Édis Milaré ressalta que a restrição ao cidadão eleitor é compensada no rol ampliado de legitimados da ação civil pública, cujos objetos transindividuais são assemelhados (MILARÉ, 2011, p. 1474-1475).

São as barreiras de acesso à Justiça que, para sucumbirem, será primordial “[...] uma outra cultura jurídica e judiciária. Uma outra formação de magistrados. Outras faculdades de direito [...]" (SANTOS, 2011, p. 38).

Aqui vale a pergunta formulada por Boaventura de Sousa Santos (2011), em obra sobre a justiça: "Se o direito tem desempenhado uma função crucial na regulação das sociedades, qual a contribuição para a construção de uma sociedade mais justa?” (SANTOS, 2011, p. 39).

Como propõe o autor, faz-se necessária "[...] uma nova concepção do acesso ao direito e à justiça", em que "[...] o acesso irá mudar a justiça a que se tem acesso." (SANTOS, 2011, p. 39). 
Claro que não se pode imputar ao Judiciário a responsabilidade por todas as querelas sociais (ou, no caso, socioambientais); por outro lado, deve-se aceitar o seu papel enquanto corresponsável na solução. (SANTOS, 2011, p. 40).

A abertura de espaço ou de acesso às pessoas em prol de direitos fundamentais, como ao meio ambiente ecologicamente equilibrado, via ação popular, por exemplo, não significa negligenciar os limites da atuação judicial, que se deve pautar em argumentos de natureza jurídica, extraídos a partir dos dispositivos constitucionais. De modo diverso, a atividade judicante seria ilegítima.

De acordo com Marcelo Cattoni, o controle judicial “[...] deveria, portanto, reforçar a dinâmica democrática, reconhecendo, inclusive, novos sujeitos e novos direitos, por meio de uma interpretação inclusiva da Constituição (art. $5^{\circ}, \S 2^{\circ}$, da Constituição brasileira)" (CATTONI, 2013, p. 41).

Não se pretende defender uma compreensão paternalista do Judiciário, mas um acesso à justiça e aos limites de atuação em consonância com os fins precípuos e à realidade fática e jurídica brasileira, com decisões legítimas, adequadas e justas.

Afinal, "o direito procura incessantemente tocar a justiça e se aproxima dela a cada instante dentro do contínuo de interpretações ao qual está sempre submetido" (OLIVEIRA; GOMES, 2011, p. 99).

Incabível retirar duplamente do cidadão o direito ao meio ambiente ecologicamente equilibrado e do judiciário a análise dessas demandas, embora ainda impregnadas de vícios que precisam ser aniquilados ou, pelo menos, minimizados. Não se pode esquecer que a democracia é uma construção permanente, e que existe constante tensão entre facticidade e validade mediando a realidade social e as pretensões normativas.

\section{CONSIDERAÇÕES FINAIS}

A crescente judicialização de demandas concernentes à efetivação de direitos fundamentais sociais tem exigido postura ativa do Judiciário e, com isso, colocado em pauta a legitimidade e os limites desse protagonismo, sobretudo no âmbito da falta estatal em implementar políticas públicas.

$\mathrm{O}$ meio ambiente ecologicamente equilibrado, erigido à categoria de direito fundamental na Constituição de 1988, enquanto primordial à existência da própria vida, e com 
qualidade, também sofre desse abandono de efetividade, posto que dotado de caráter social prestacional.

Os dispositivos constitucionais permitem uma interpretação equânime e solidária do que se objetiva para a sociedade brasileira, implicando no dever de cuidado e responsabilidade do Poder Público, em sentido amplo, com a matéria ambiental.

O discurso comum da Administração, no entanto, é a falta de recursos financeiros para concretização de suas obrigações com a população, argumento que não pode ser repetido, de forma exclusiva, pelo Poder Judiciário, cujo papel está imbricado com premissas jurídicas e não políticas.

A conduta omissiva deve sempre se deparar, por outro lado, com atitudes enérgicas, pelo cidadão, destinatário do direito, mas imbuído da tarefa de proteger o que lhe é mais estimado por meio da instância última de alento consubstanciado na decisão corretiva do Judiciário.

A ação popular, o instrumento judicial mais antigo a favor da sociedade, a fim de possibilitar o acesso e a busca por resoluções às ofensivas ambientais, não deveria restringir a legitimidade ativa de sua propositura aos eleitores, que não são os únicos a sofrerem os efeitos de um ambiente desequilibrado.

A par das críticas que possam ser feitas, que servem como evolução e não óbice, a atuação judicial se faz necessária para o controle na execução dos direitos expressamente preconizados constitucionalmente, respeitadas as delimitações da própria norma suprema, e as variáveis do caso concreto.

E o cidadão não pode ter ainda mais inacessível o direito socioambiental se há meios próprios à sua disposição para tutelá-lo, em virtude de requisitos ultrapassados quando comparados à dinâmica e especificidade da modernidade, os quais devem ser constantemente revisitados como medida de verdadeira justiça.

O desafio é remodelar o aparato judicial brasileiro, o que requer muita vontade política à mingua de vaidade e interesses espúrios, com reformulação da própria formação dos juristas, sempre em consonância com a salvaguarda dos bens mais importantes, incluindo a própria existência humana.

\section{REFERÊNCIAS}


APPIO, Eduardo. Controle judicial das políticas públicas no Brasil. Curitiba: Juruá, 2007.

BARROSO, Luís Roberto. Interpretação e aplicação da constituição: fundamentos de uma dogmática constitucional transformadora. 7. ed. rev. São Paulo: Saraiva, 2009.

BRASIL, Assembleia Nacional Constituinte. Constituição da República Federativa do Brasil. Brasília: Imprensa Nacional. Diário Oficial da União, 05 de outubro de 1988. Disponível em: <http://www.planalto.gov.br/ccivil03/constituicao/constitui\%C3\%A7ao.htm>. Acesso em: 22 fev. 2017.

BRASIL, Congresso Nacional. Lei n. 4.717, de 29 de junho de 1965. Brasília: Imprensa Nacional. Diário oficial da União, 5 de julho de 1965. Disponível em: <http://www.planalto.gov.br/ccivil_03/leis/L4717.htm>. Acesso em: 22 fev. 2017.

BRASIL, Congresso Nacional. Lei n. 7347, de 24 de julho de 1985. Brasília: Imprensa Nacional. Diário oficial da União, 25 de julho de 1955. Disponível em: < https://www.planalto.gov.br/ccivil_03/LEIS/L7347orig.htm>. Acesso em: 22 fev. 2017.

BRASIL, Congresso Nacional. Lei n. 6938, de 31 de agosto de 1981. Brasília: Imprensa Nacional. Diário oficial da União, 02 de setembro de 1981. Disponível em: <http://www.planalto.gov.br/ccivil_03/leis/L6938.htm>. Acesso em: 22 fev. 2017.

BRASIL. Supremo Tribunal Federal. ADPF 45 MC/DF. Rel. Min. Celso de Mello. 2004. Disponível em: <http://www.stf.jus.br/arquivo/informativo/documento/informativo345.htm>. Acesso em: 14 jan. 2017.

CATTONI, Marcelo. Jurisdição constitucional, democracia e judicialização da política: considerações a partir da PEC n. 3, de 10 de fevereiro de 2011. Revista Brasileira de Direito. IMED. Vol. 9, n. 2, p. 38/46, jul./dez., 2013.

COSTA, Beatriz Souza. Meio ambiente como direito à vida: Brasil, Portugal, Espanha. Belo Horizonte: Editora O Lutador, 2010.

COSTA, Beatriz Souza; REIS, Emilien Vilas Boas; OLIVEIRA, Márcio Luís. Fundamentos filosóficos e constitucionais do direito ambiental. Rio de Janeiro: Lumen Juris, 2016.

CRUZ, Álvaro Ricardo de Souza. Hermenêutica jurídica e(em) debate. O constitucionalismo brasileiro entre a teoria o discurso e a ontologia existencial. Belo Horizonte: Forum, 2007.

DWORKIN, Ronald. Levando o direito a sério. Tradução Nelson Boeira. São Paulo: Martin Fontes, 2002.

1999.

O império do direito. Tradução Jefferson Luiz Camargo. São Paulo: Martins Fontes,

FERNANDES, Gonçalves Bernardo. Curso de direito constitucional. 5ed. Salvador: 
JusPodivm, 2013.

FIORILlO, Celso Antônio Pacheco. Curso de direito ambiental brasileiro. São Paulo: Saraiva, 2014.

FULGÊNCIO, Paulo Cesar. Glossário VadeMecum: administração pública, ciências contábeis, direito, economia, meio ambiente. Rio de Janeiro: Mauad, 2007.

GIONGO, Rafaela Luiza Pontalti. Direito ao meio ambiente e qualidade de vida: reflexões para uma sociedade humana e ecológicamente viável. Revista Veredas do Direito, Belo Horizonte: v.7, n. 13/14, pp. 75/100, jan./dez. 2010.

GRINOVER, Ada Pelegrini; WATANABE, Kazuo (Coord.). O controle jurisdicional de políticas públicas. 2. ed. Rio de Janeiro: Forense, 2013.

HABERMAS, Jurgen. Direito e Democracia: entre facticidade e validade. Vol. II. Trad. Flávio Beno Siebeneichler. Rio de Janeiro: Tempo Brasileiro, 2011.

HOUAISS, Antonio. Minidicionário Houaiss da língua portuguesa. 4. ed. Rio de Janeiro: Objetiva, 2010.

JONAS, Hans. O princípio vida: fundamentos para uma biologia filosófica. Trad. Carlos Almeida Pereira. 2. ed. Rio de Janeiro: Editora Vozes, 2004.

, Hans. O princípio da responsabilidade: ensaio de uma ética para a civilização tecnológica. Trad. Marijane Lisboa e Luiz Barros Montez. Rio de Janeiro: Contraponto, Ed. PUC Rio, 2006.

KISS, Alexandre. Os direitos e interesses das gerações futuras e o princípio da precaução. In: VARELlA, Marcelo Dias; PLATIAU, Ana Flávia Barros. Princípio da Precaução. Belo Horizonte: Del Rey, 2004.

LAKATOS, Eva Maria; MARCONI, Marina de Andrade. Metodologia científica. 4. ed. São Paulo: Atlas, 2006.

MACHADO, Paulo Affonso Leme. Direito ambiental brasileiro. 22. ed. São Paulo: Malheiros, 2014.

MILARÉ, Édis. Direito do ambiente: doutrina, jurisprudência, glossário. 7. ed. São Paulo: Editora Revista dos Tribunais, 2011.

MINAS GERAIS. Tribunal de Justiça. Apelação Cível n. 10082120006448001. Rel. Desemb. Heloisa Combat. Diário de Justiça, 14 de junho de 2016. Disponível em: <http://tjmg.jusbrasil.com.br/jurisprudencia/351386308/apelacao-civel-ac-10082120006448001mg/inteiro-teor-351386350>. Acesso em: 23 nov. 2016.

NEVES, Rodrigo Fernandes das. Ativismo judicial: objeções à intervenção do judiciário na formulação e execução de políticas públicas ambientais. Disponível em: 
http://www.procuradoria.al.gov.br/centro-de-estudos/teses/Xxxv-congresso-nacional-deprocur adores-de-estado/direito-ambiental/ATIVISMO\%20JUDICIAL\%20-\%20OBJECOES\%20A \%20INTERVENCaO\%20DO\%20JUDICIARIO\%20NA\%20FORMULACaO\%20E\%20EXE CUCaO\%20DE\%20PO LITICAS\%20PUBLICAS.pdf>. Acesso em: 22 fev. 2017.

OLIVEIRA, Marcelo Andrade Cattoni de; GOMES, David Francisco Lopes. A justiça e a democracia como hipérbole. Revista de Estudos Constitucionais, Hermenêutica e Teoria do Direito. P. 95/101, jan./jun., 2011.

RIO DE JANEIRO. Tribunal Regional Federal 2. Apelação Cível n. 200650030001363. Rel. Desemb. Federal NIZETE LOBATO CARMO. Diário de Justiça, 3 de novembro de 2014. Disponível em: <http://trf-2.jusbrasil.com.br/jurisprudencia/160028851/apelacao-civel-ac200650030001363-rj/inteiro-teor-160028964>. Acesso em: 23 fev. 2017.

ROCHA, Carmen Lúcia Antunes. Ação Afirmativa - o conteúdo democrático do princípio da igualdade jurídica. Revista de Informação Legislativa do Senado Federal. Brasília, n. 131, p. 283/295, jul./set., 1996.

SANTOS, Boaventura de Sousa. Para uma revolução democrática da justiça. 3.ed. São Paulo: Cortez, 2011.

SILVA, José Afonso da. Curso de direito constitucional positivo. 31.ed. rev. e atual. São Paulo: Malheiros Editores, 2008.

SILVA, José Afonso da. Direito ambiental constitucional. 10.ed. São Paulo: Malheiros, 2013.

SOUZA, Jessé. Ralé brasileira: quem é e como vive. Belo Horizonte: UFMG, 2009.

STRECK, Lênio Luiz. Hermenêutica jurídica em crise: uma exploração hermenêutica da construção do Direito. 11. ed. Porto Alegre: Livraria do Advogado, 2014.

SUPREMO TRIBUNAL FEDERAL. Ação Direta de Inconstitucionalidade n. 3.943 DF. Rel. Min. Cármen Lúcia. Diário de Justiça, 6 de agosto de 2015. Disponível em: $<$ http://redir.stf.jus.br/paginadorpub/paginador.jsp?docTP=TP\&docID=9058261 >. Acesso em 23 fev. 2017.

THOMÉ, Romeu. O princípio da vedação do retrocesso socioambiental no contexto da sociedade de risco. Salvador: JusPodivm, 2014.

VILELA, Bruna Luíza Capellini; FRANÇA, Verônica Maria Ramos do Nascimento. Os métodos interpretativos de Ronald Dworking para solução de conflitos ambientais no ordenamento jurídico brasileiro.In: REIS, Émilien Villas Boas (ORG). Entre a filosofia e o ambiente: bases filosóficas para o direito ambiental. Belo Horizonte: 3i Editora, 2014. 